\title{
Readmissions, Mortality and HRRP: The bane of a cardiac surgeon's existence!
}

\author{
Abdullah Nasif ${ }^{1}$ and Saqib Masroor ${ }^{2}$ \\ ${ }^{1}$ The University of Toledo Medical Center \\ ${ }^{2}$ University of Toledo Medical Center
}

June 8, 2021

\section{Hosted file}

HRRP Invited Com - Draft 5.docx available at https://authorea.com/users/415675/articles/ 525371-readmissions-mortality-and-hrrp-the-bane-of-a-cardiac-surgeon-s-existence 